\title{
Multiple perspectives in design: World maps and their perspectives
}

\author{
Julia Mia Stirnemann / Bern University of Applied Sciences / University of Bern / \\ University of Zurich / Switzerland
}

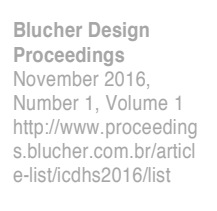

\begin{abstract}
The depiction of the world by means of world maps makes design perspective an issue of cartography. In design issues, world maps have different purposes, such as in the field of information graphics. The geographical centres of conventional world maps are usually defined by the Equator that forms the horizontal axis, rather than by the thematically relevant geographical area of the map's topic. Conventional world maps are commonly used without much thought to the relationship between the map's theme and its geographical centre. These prevailing conventions are responsible for the specific worldview that emerges from a unique perspective and a unique ideological point of view. This raises the question: what if world maps could be designed with different perspectives? "Mapping World Maps" answers this question by proposing a principle for generating unconventional world maps. Special-purpose software has now been developed (www.worldmapgenerator.com) to generate wholly new varieties of world maps.
\end{abstract}

\section{Keywords}

Visual communication, cartography, generative graphics, world maps, viewpoints

\section{Introduction: Maps, a matter of visual communication}

In visual communication, maps are an important means of depicting information. Maps are visual depictions that are not merely a matter for cartographers. However, it is rare for world maps to be applied in visual communication in a manner that takes their possible variations into account. For world maps are subject to conventions by which they are usually depicted from the same ideological and constructive perspective. These conventions are responsible for how we depict our world. Above and beyond this, the boundaries between the disciplines of cartography and visual communication are vague, which can be explained by a glance into their history (Papay, 2012). The artificial division of the concept of the "map" from that of the "image" only began to make itself felt at the close of the $16^{\text {th }}$ century, according to which cartographic depictions were assigned to the field of "cartography". Today, maps are of great significance in visual communication, not least in connection with "visual sign systems". One important representative of an interdisciplinary approach is Jacques Bertin, who presented his "Sémiologie graphique" both in specialist cartographic journals and in the field of visual communication (Bertin, 2001). One of the things that Bertin demonstrated was how "variables of the second dimension" create a basis for cartographic diagrams - and this also offers a basis for cartographic infographics (Bertin, 1967). This graphic/cartographic idea played an important role in the visual communication discourse (Daru, 2001) and was taken up by Edward Tufte, whose fundamental works on visual communication refer to infographics (Tufte, 1990).

The project described below is based on a critical inventory of the design and construction of cartographic fundamentals for visual depictions, and it places its focus on world maps. It is not the depiction of data (infographics) or narratives (storytelling) that is foregrounded here; world maps are instead regarded as "basic maps", thus as a basis for a visual depiction. The following research goals were pursued. 1. Comprehending the construction and design of world maps, and adopting a broad variety of possible world maps. 2. Applying world maps to different contexts of usage; this will be demonstrated by means of the applications (Da Vinci, Tourist, Journalist) of the software that has been developed for the purpose, namely worldmapgenerator.com; and 3. Elaborating the socio-cultural dimension of multiple perspectives of world maps, and reviewing assumptions of their neutrality. Finally, methodological deficits will be identified within the framework of the project and alternative solutions presented. World maps are determined by standardisations whereby the constructive aspect of a world map is substantially determined by its "projection": ${ }^{1}$ this projection is responsible for the mathematical derivation of the map's flat surface from the Earth's

\footnotetext{
${ }^{1}$ For simplicity's sake, we ignore here the precise difference between the concepts of "projection" and "Kartennetzentwurf" (literally
} 
spherical surface, and is responsible for the image proportions of the world map. It also defines the region that is depicted in the centre of the image. However, there are hardly any maps in use that have shifted an alternative geographical centre to the middle of the image. The possibilities for depicting the region in the centre of the image are by no means exhausted and are in fact currently highly restricted.

\section{Methodological concepts for constructing world maps and alternative possibilities}

Turning the surface of the globe into a two-dimensional map involves an abstract mathematical transformation from a sphere into a two-dimensional plane. An algorithm is needed for this transformation, which is called a "projection" in the cartographic process. This projection always subjects the world map to distortion, because a distortion-free depiction of the surface of the globe is an impossibility in a world map. Just think of a conventional world map in which North is at the top and whose top and bottom margins are determined by the North and South Poles respectively. We immediately see that certain regions have been distorted. Thus, for example, the Antarctic appears as a long strip at the bottom of the image, while Greenland abandons all notion of fidelity to its real form and surface area. World maps possess their own characteristics that are determined by their projection and their degree of distortion. There is currently a broad variety of projections that can be subdivided into tangential, planar, equidistant or mediating projections. These different types of projection also differ in their form. Some world maps are square, others are round, curved or even star-shaped. ${ }^{2}$ The choice of projection and the choice of the geographical centre for the middle of the image are responsible for the form of the Earth's surface.

In order to achieve a broad variety of different world maps, we here introduce a new principle for generating them. When constructing unconventional world maps, the mathematical transformation of the surface of the globe onto a two-dimensional plane remains the same. The unconventional aspect of this principle is oriented on the extant algorithms for projections, and merely rethinks the region to be depicted in the middle of the image. This is carried out by a flexible positioning of the great circle. ${ }^{3}$ In other words, whereas in conventional world maps the great circle of the Equator usually lies in the horizontal centre of the image, unconventional world maps can place the great circle in any desired position (see Fig. 1). These unconventional world maps are still subject to the same degree of distortion.
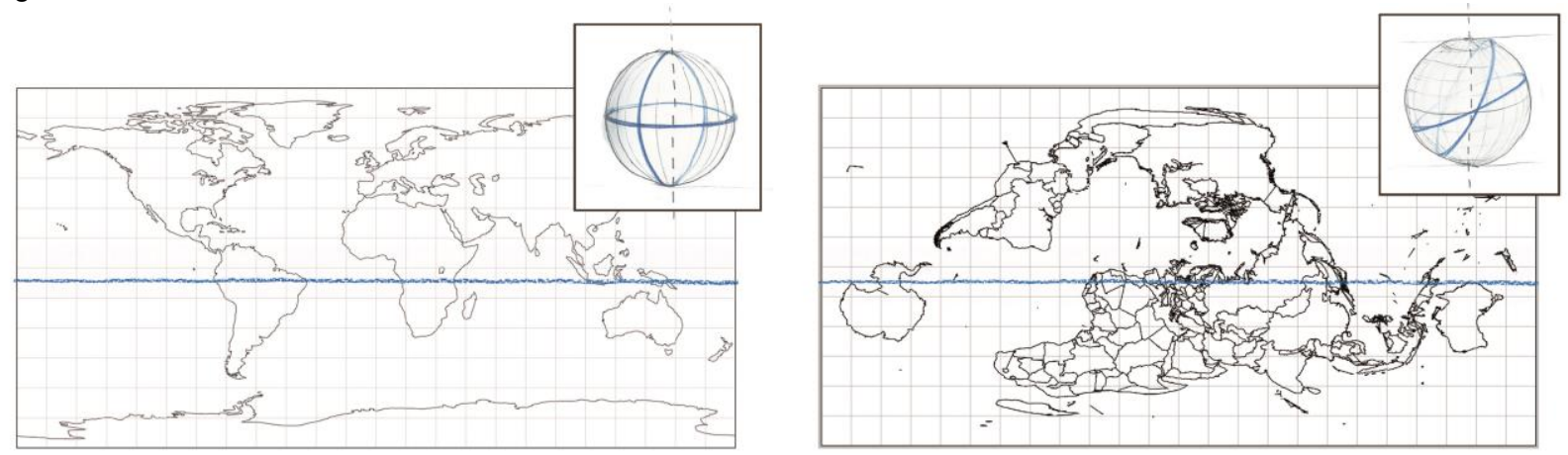

Fig. 1: Great Circle: Left - plate carée projection, with the Equator at the horizontal centre. Right - plate carée projection with a freely chosen geographical centre.

Besides unconventional constructions of world maps, different possibilities for depicting the world also allow for a broad variety of world maps. Conventional attributes can be rethought, such as the colours given to geophysical elements. Thus the mass of water need no longer be depicted as blue.

In order to achieve a broad variety of possible world maps, a new software program has been developed (www.worldmapgenerator.com). It allows for unconventional world maps to be generated in which the

"map net draft"). To be precise, a projection is the strictly mathematical transformation of the three-dimensional globe onto a twodimensional plane. A "Kartennetzentwurf" on the other hand can signify a modified transformation of this procedure in which the conversion can be influenced by other parameters that have been determined elsewhere. These concepts are often used imprecisely in the field of cartography. The "Robinson projection", for example, is not really a "projection" but a mediating "Kartennetzentwurf". The present article uses the term "projection" throughout. (Bollmann, 2001) pp. $440-443$.

${ }^{2}$ Compare, for example, square: Miller or Merkator projections; round: azimuthal projections; curved: Eckert or Robinson projections; star-shaped: Waterman projection. These and other projections can be chosen freely at www.worldmapgenerator.com .

${ }^{3} \mathrm{~A}$ great circle is the largest possible circle on the surface of a sphere. The Equator and the Meridians are great circles. Theoretically, an infinite number of great circles could be placed around the globe. 
geographical centre of a world map can now be determined independently of the chosen projection (Fig. 2). The result is unconventional world maps whose image proportions offer alternatives to hitherto world maps. This Worldmapgenerator is freely available online and enables an interested public to create just such unconventional world maps. Every user can generate his or her own individual world map in which the geographical centre and the projection can be chosen freely.
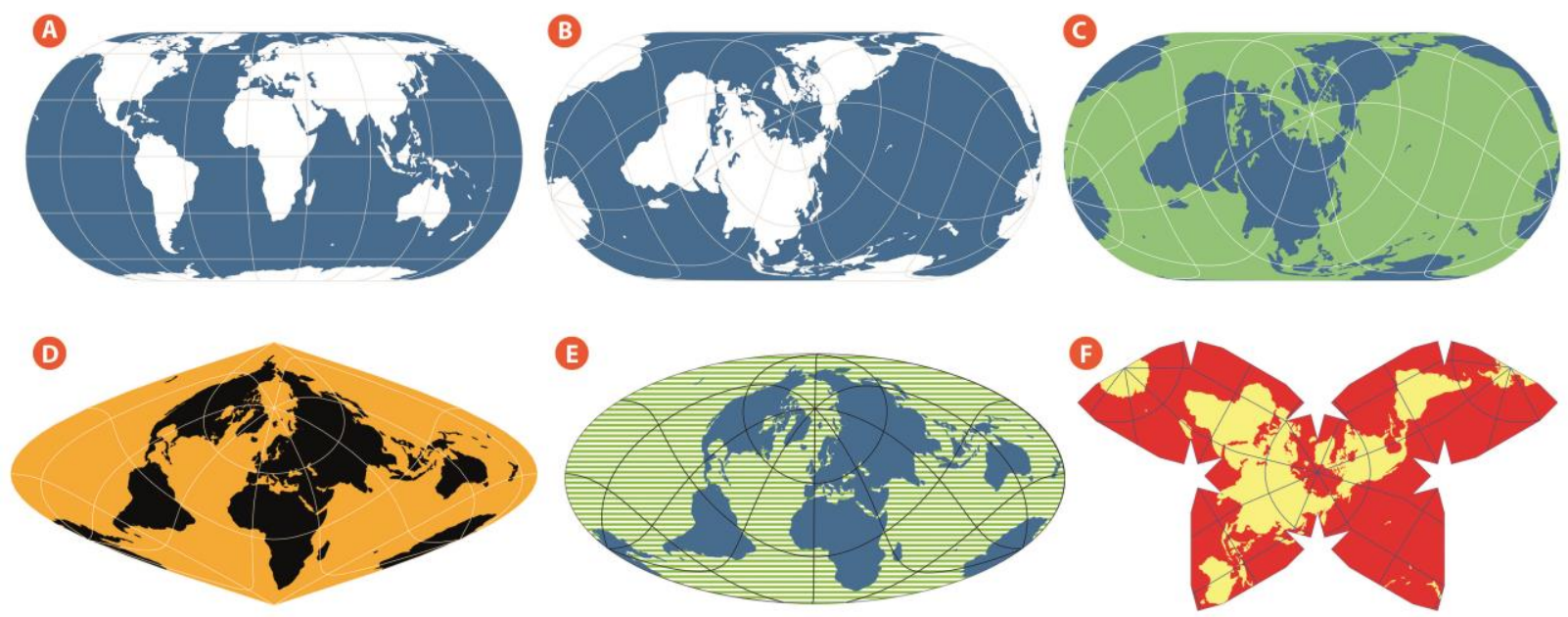

Fig. 2, A - C: Different world maps in an Eckert IV projection: A. World map centred on Equator B. World map centred on any desired geographical area C: World map centred on any desired geographical area, with an unconventional design

Fig. 0, D - F: World maps centred on any desired geographical area, with unconventional designs: D: Sinusoidal-projection, E: Mollweide projection, F: Waterman projection

\section{Potential contexts for applying unconventional world maps, with concrete examples}

Maps are employed in visual communication as "representations of geospatial data" or as "geo-data carriers" that form the basis of a graphic visualisation. Maps serve as a medium for conveying information, creating a frame of reference that can be employed in different ways as a "ground plan", a "basic board" or an "image plane". The scope of allocation of cartographic visualisations is correspondingly varied - we just have to think of information visualisations of storytelling. Maps give a location to data in infographics, they visualise statistics, accompany literary works (such as "The Land of Oz", "The Hobbit" etc.), they embody imaginary worlds in films and computer games, are used for propaganda purposes, and illustrate travel guides for cities, etc. (Caquard, 2015). Different types of maps are envisaged for all these different uses and they can be accordingly employed for graphic applications, as in the case of city maps, weather maps, top-view maps, metro maps etc. They utilise different design means in different ways such as typography, map layout, symbols, colours etc. ${ }^{4}$

Unconventional world maps call certain aspects of the conventional perspective of the world into question. World maps are not an objective, faithful depiction of the surface of the globe. It is obvious that world maps do not just depict geophysics in the best possible, abstract form, but also always convey a subjective world outlook (Harley, 1989, 2001). This socio-cultural dimension in world maps and the worldviews associated with it are placed in a theoretical framework and illustrated below by means of examples using the three applications developed in the course of the current project, namely "Da Vinci", "Journalist" and "Tourist" (Stirnemann, 2014).

When opening Worldmapgenerators.com, three applications appear on the start page that can be employed to meet different graphic needs (Fig. 3).

The "Da Vinci" application offers access to individually generated world maps that question conventions of map depiction and the worldviews associated with them. This application enables one to construct and design unconventional world maps. In an initial step, an interactive "globe world map model" allows one to define the geometrical depiction of the world map (Fig. 4). This interactive model enables the user to follow the transformation of the globe's surface into the two-dimensional world map in real time. The geographical region placed in the

\footnotetext{
${ }^{4}$ In the fields of design and art, more and more publications are appearing with cartographic content. This variety of publications makes it evident that cartographic content has long been appropriated by graphic design. See (Akerman, 2007) - (Barber, Harper, \& British Library (London), 2010) - (Barber, 2005) - (Antoniou, 2013) etc.
} 
centre of the image can be shifted by means of the ball and the map, with the contact point of the image ${ }^{5}$ being displayed synchronously. The second step enables the user to design the unconventional world map. Colours, patterns and line thickness can be adjusted for assorted geo-features such as land and water masses, country boundaries, the map grid and individual countries etc. The free choice of design parameters means that the design of the world maps can turn out to be very unconventional indeed.
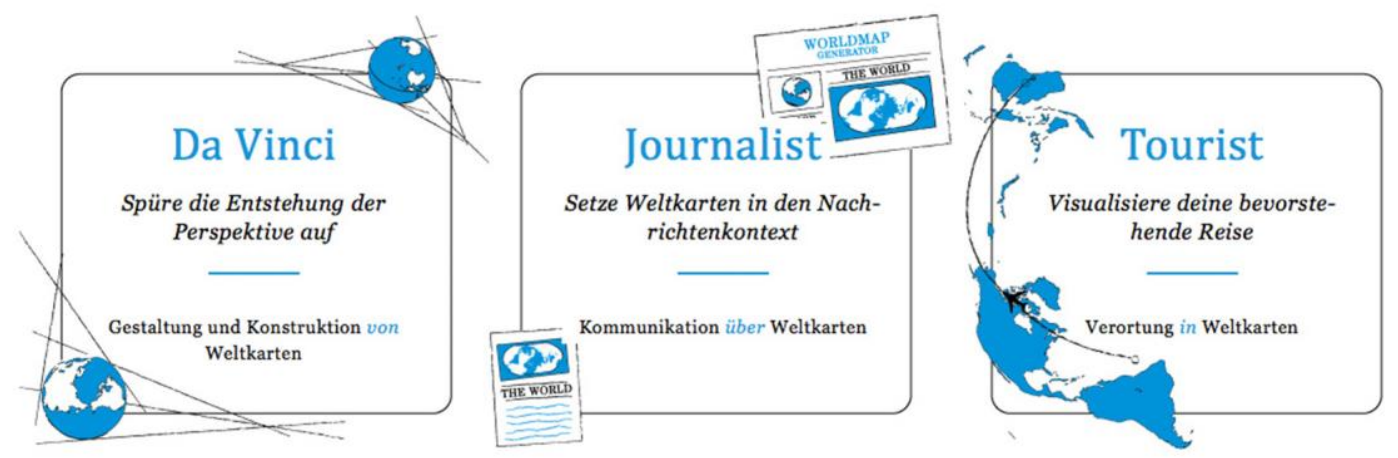

Fig. 3: Start page, worldmapgenerator.com with the three applications: Da Vinci, Journalist, Tourist

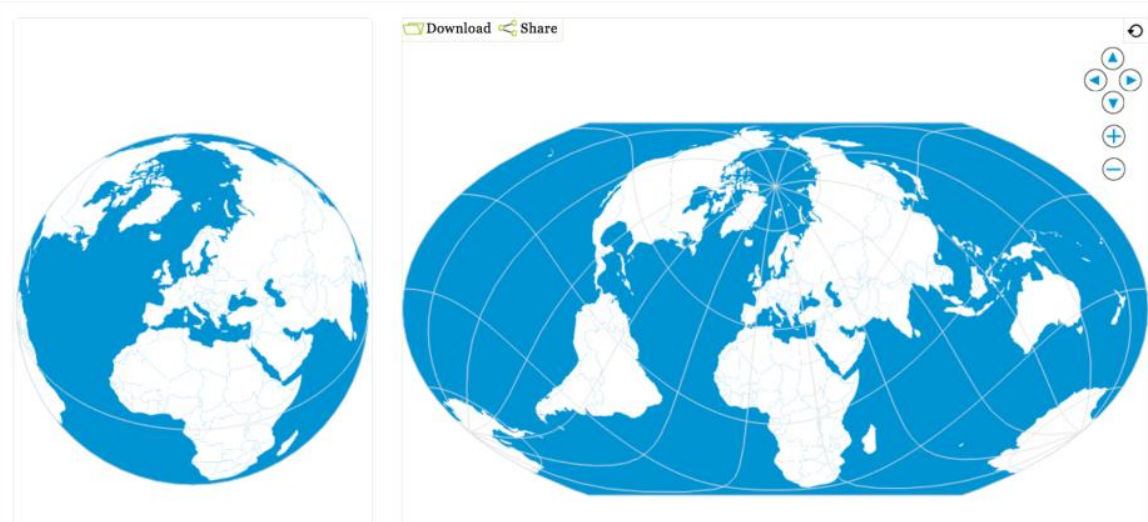

PROJECTION: $9080 \square 00$ म Wagner IV

Fig. 4: Interactive globe map model using the "Da Vinci" application.

The frame of reference of any graphic depiction is never unbiased. "Da Vinci" demonstrates that even world maps are not neutral, two-dimensional depictions. They present the surface of the globe but are not visualisations of reality. Instead they represent a strongly abstract space at a specific point in time. Current world maps comprise a synthesis of different signs that results in the map picture. This map picture is subject to specific conventions that are in turn determined by their cultural context and the motives of the person creating the map. The reception of a map is also dependent on the conditioning of the observer. Interpreting visual codes depends both on the conventions for a map's depiction that have evolved through history and on the observer's socio-cultural particularities. Consequently, it is impossible to achieve a universally valid, unique interpretation of a map. It remains individual and dependent on the observer's world view.

The "Journalist" application places the unconventional world maps in a communication context, namely in the context of news headlines. Two modes are available for this. The news can either be read or written; thus the user either reads the news that is generated by the RSS feed, or designs his own headline. The construction and design of the world map is carried out by a generative process by means of which variables of construction and design are combined with one another to produce the corresponding world map. World maps suitable as images for newspaper articles are generated in both modes. From a constructional point of view, the centre of the world map is adjusted to the place featured in the news headline. So, for example, if the headline runs:

\footnotetext{
${ }^{5}$ By "contact point of the image", we mean the foot of the perpendicular of the centre of the projection, here of the world map.
} 
"With new climate draft, a deal creeps closer in Paris", ${ }^{6}$ then the world map is subjected to an automatic process that focuses it on Paris. From a design perspective, the world map is created from a combination of a predefined number of design variables. A variety of different combinations of variables can lead to many different world map designs.

Graphic representations using world maps are often determined by a specific underlying intention: they are a visualisation of power and politics. For visual communication, depictions of so-called "suggestive" maps are of particular relevance. These have an emotional impact and subliminally convey a specific conviction. Arnold Hillen Ziegenfeld (1935) created the expression "cartographic" for just such a map type that emerged in analogy to the then emerging field of commercial graphic art. The unconventional world maps that appear in the "Tourist" application in connection with the daily headlines compel us to adopt a new, content-related perspective to political events.

The "Tourist" application enables the user to depict and measure distances around the globe. Here, routes are drawn between different destinations. The application then shows the degree to which the route drawn is subjected to the distortion of the world map. By adjusting the centre and the projection of the world map, a shift occurs in the length of the routes that are drawn, though their effective distance remains unchanged. In other words, if one were to travel from Taipei to Zurich, from Zurich to Montreal, from Montreal to Buenos Aires and then from Buenos Aires to Taipei, the distance of the route would measure $43,528 \mathrm{~km}$ in total. In Fig. 5, this route is depicted from the perspective of Taipei, and then from the perspective of Zurich. These visualisations demonstrate clearly that the distance of the route remains effectively the same, but its form can appear very different according to the centre point chosen.

The manifestations of basic graphic depictions are always influenced by a specific subjective standpoint that results from a subjective perspective, and thus also represents a subjective worldview. Creating and using cartographic depictions is always determined by a subjective reference point. So it is all the more important to ask questions about the standpoint of the individual. In the "Tourist" application this is documented by shifting the map's centre point.

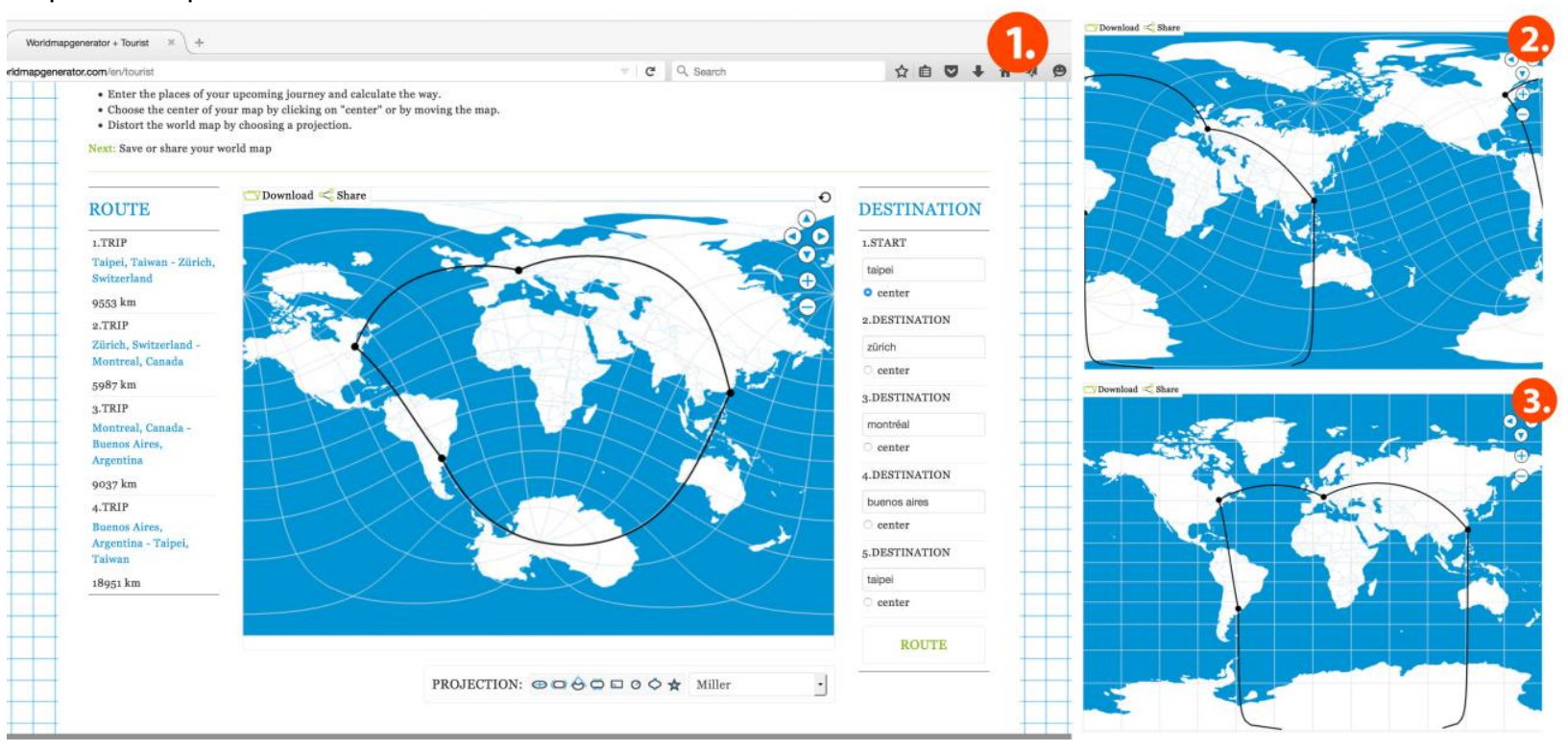

Fig. 5: Tourist application: Route depicted: Taipei - Zurich; Zurich - Montreal; Montreal - Buenos Aires; Buenos Aires - Taipei. 1. Interface with world map centred on Africa 2. World map centred on Taipei 3. World map centred on Zurich.

\section{Discussion}

Cartographic depictions are widely used in the field of visual communication. As "data carriers" they often create a frame of reference for visualisations of information. This graphic basis is employed for different graphic products, such as for info-graphics or storytelling. But these are not value-free. On the contrary, they are determined by conventions of depiction that have emerged over time and have correspondingly conditioned our ability to interpret them. This is where the software worldmapgenerator.com comes into the equation: this software questions conventions of design and construction in world maps by enabling users to generate subjective maps. They can choose any geo-

\footnotetext{
${ }^{6}$ Reuters headline on Wednesday, 9 December 2015.
} 
graphical centre for the map and modify the world map by means of different design options. Using the three applications (Da Vinci, Journalist and Tourist) demonstrates that the unconventional world maps all refer to a communication context. Ultimately, the sociocultural dimension of world maps is made evident and discussed with regard to the worldview that they represent. We can conclude from this that cartographic depictions can be applied in different fields in visual communication. This is why questioning their ideological and constructional perspective is of great importance. Worldmapgenerator.com offers a suggestion as to how multiple visual perspectives can be applied to world maps.

\section{Acknowledgement}

This paper is based on research conducted for a project funded by the SNSF (Swiss National Science Foundation): "Mapping Worldmaps" (project number: 100016 156136). The author would like to express her warm thanks to Dr rer. pol. Dr h.c. Harald Klingemann of the Bern University of the Arts for his valuable advice during the revision of earlier versions of the present article.

\section{References}

Akerman, James R. (2007). Maps - finding our place in the world. Chicago, III.: University of Chicago Press. Antoniou, Antonis. (2013). A map of the world according to illustrators \& storytellers. Berlin: Gestalten. Barber, Peter. (2005). The map book. London: Weidenfeld \& Nicolson.

Barber, Peter, Harper, Tom, \& British Library (London). (2010). Magnificent maps power, propaganda and art. London: The British Library.

Bertin, Jacques. (1967). Sémiologie graphique les diagrammes - les réseaux - les cartes. Paris: Mouton. Bertin, Jacques. (2001). Matrix theory of graphics. Information design journal : IDJ, 10 (1), 5-19.

Bollmann, Jürgen. (2001). Lexikon der Kartographie und Geomatik in zwei Bänden. Berlin: Spektrum. Caquard, Sébastien. (2015). Narrative and Cartography. In M. Monmonier (Ed.), The History of Cartography (Vol. Volume II, pp. S. 989 - 991). Monmonier, Mark: University of Chicago Press.

Daru, Myriam. (2001). Jacques Bertin and the garphic essence of data. Information design journal : IDJ, 10 (1), 20-25.

Harley, J. B. (1989). Deconstructing the map. Cartographica, 26, S. $1-20$.

Harley, J. B. (2001). The New Nature of Maps. Baltimore, London: The Johns Hopkins University Press. Papay, Gyula. (2012). Gedanken zur Kartographie als Bild- und Raumwissenschaft. Kartografische Nachrichten, 62(1), 3 - 9.

Stirnemann, Julia Mia. (2014). Multiple Alternativen zur Konstruktion und Gestaltung von Weltkarten. Kartographische Nachrichten, 1(Jg. 64), S. 17-21

Tufte, Edward Rolf. (1990). Envisioning information. Cheshire, Connecticut: Graphics Press.

\section{Biographical note}

Julia Mia is a graphic designer, an artistic researcher and a freethinker. She challenges viewpoints and likes to contemplate the world upside-down. For that she developed the software www.worldmapgenerator.com. Julia Mia is in the process of completing a PhD. She has several years of work experience as a graphic designer and today runs her own design studio (www.juliamia.ch). 